\title{
Prediction of Locally Advanced Urothelial Carcinoma of the Bladder Using Clinical Parameters before Radical Cystectomy - A Prospective Multicenter Study
}

\author{
Thomas Martini ${ }^{a}{ }^{r} \quad$ Atiqullah Aziz ${ }^{b}$ Florian Roghmann ${ }^{c} \quad$ Michael Rink ${ }^{b}$ \\ Felix K. Chun $^{b}$ Margit Fisch ${ }^{b}$ Lutz Trojan ${ }^{d}$ Oliver W. Hakenberg ${ }^{\text {e }}$ Stefan Zastrow ${ }^{f}$ \\ Manfred P. Wirth ${ }^{f}$ Johannes Moersdorfa Sabine Brookman-May ${ }^{g}$ Christian G. Stiefg \\ Axel Haferkamp $^{\mathrm{h}}$ Florian Wagenlehner ${ }^{\mathrm{i}} \quad$ Markus Hohenfellner $^{\mathrm{j}}$ Edwin Herrmann $^{\mathrm{k}}$ \\ Lukas Lusuardi $^{u}$ Marc-Oliver Grimm' Stephan C. Müllerm Jan Roigas ${ }^{n}$ \\ Patrick J. Bastian ${ }^{\circ}$ Michael Gierth ${ }^{p}$ Maximilian Burger ${ }^{p} \quad$ Armin Pycha $^{r}$ \\ Christian Seitz $^{\mathrm{s}, \mathrm{t}}$ Matthias May ${ }^{\mathrm{q}}$ Christian Bolenz $^{\mathrm{a}}$
}

a Department of Urology, Mannheim Medical Center, University of Heidelberg, Mannheim, ${ }^{b}$ Department of Urology, University Medical Centre Hamburg-Eppendorf, Hamburg, 'Department of Urology, Marienhospital, Ruhr-University Bochum, Herne, ${ }^{d}$ Department of Urology, University Medical Center Göttingen, Göttingen, e Department of Urology, Universitätsmedizin Rostock, Rostock, ' Department of Urology, University Hospital 'Carl Gustav Carus', University of Technology, Dresden, ${ }^{9}$ Department of Urology, Ludwig-Maximilians-University, Munich, h Department of Urology, Goethe-University Frankfurt, Frankfurt am Main, 'Department of Urology, Pediatric Urology and Andrology, Justus Liebig University of Giessen, Giessen,

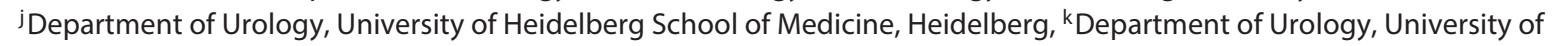
Muenster Medical Center, Muenster, 'Department of Urology, Jena University Hospital, Jena, m Department of Urology, University of Bonn, Bonn, n'Department of Urology, Vivantes Medical Centre Im Friedrichshain and Am Urban, Berlin,

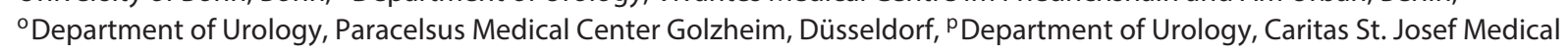
Center, University of Regensburg, Regensburg, and ' Department of Urology, St. Elisabeth Medical Center, Straubing, Germany; ' Department of Urology, General Hospital of Bolzano, Bolzano, Italy; ${ }^{\mathrm{s} D e p a r t m e n t ~ o f ~ U r o l o g y ~ a n d ~ A n d r o l o g y ~}$ Barmherzige Brüder, Vienna, 'tDepartment of Urology, Vienna General Hospital, Medical Universitiy of Vienna, Vienna, and uDepartment of Urology and Andrology, Paracelsus Medical University Salzburg, Salzburg, Austria

\section{Key Words}

Bladder cancer · Radical cystectomy · Nomogram · Outcome
UCB were prospectively collected and eligible for final analysis. Univariate and multivariate logistic regression models were applied to identify significant predictors of locally advanced tumor stage ( $\mathrm{pT} 3 / 4$ and/or $\mathrm{pN}+$ ) at RC. Internal validation was performed by bootstrapping. The decision curve analysis (DCA) was done to evaluate the clinical value. Results: The distribution of tumor stages pT3/4, pN+ and pT3/4 and/

T.M. and A.A. contributed equally to this work.

\section{KARGER}

E-Mail karger@karger.com

www.karger.com/uin

\begin{abstract} logical parameters. Materials and Methods: Multicenter data from 337 patients who underwent radical cystectomy (RC) for
\end{abstract}

(c) 2015 S. Karger AG, Base

0042-1138/15/0961-0057\$39.50/0
Christian Bolenz, MD and Thomas Martini, MD

Department of Urology, Mannheim Medical Center University of Heidelberg, Theodor-Kutzer-Ufer 1-3 DE-68167 Mannheim (Germany)

E-Mail christian.bolenz@umm.de and thomas.martini@umm.de 
or pN+ at RC was $44.2,27.6$ and $50.4 \%$, respectively. Age (odds ratio (OR) 0.980; $p<0.001$ ), advanced clinical tumor stage (cT3 vs. cTa, cTis, cT1; OR 3.367; $\mathrm{p}<0.001$ ), presence of hydronephrosis (OR 1.844; $p=0.043$ ) and advanced tumor stage T3 and/or $\mathrm{N}+$ at $\mathrm{CT}$ imaging (OR 4.378; $\mathrm{p}<0.001$ ) were independent predictors for $\mathrm{pT} 3 / 4$ and/or pN+ tumor stage. The predictive accuracy of our nomogram for pT3/4 and/or pN+ at RC was $77.5 \%$. DCA for predicting pT3/4 and/or pN+ at RC showed a clinical net benefit across all probability thresholds. Conclusion: We developed a nomogram for the prediction of locally advanced tumor stage pT3/4 and/or pN+ before RC using established clinicopathological parameters.

(c) 2015 S. Karger AG, Basel

\section{Introduction}

Locally advanced tumor stages, including pathologic tumor stages $\mathrm{pT} 3 / 4$ and/or lymph node involvement $(\mathrm{pN}+)$ of urothelial carcinoma of the bladder (UCB) in patients undergoing radical cystectomy (RC) are associated with high treatment failure rates and reduced disease-specific survival [1]. Clinical tumor stage based on transurethral resection of the bladder (TUR-BT) shows a considerable discrepancy when compared with the final pathologic stage obtained from the RC specimen. It has been demonstrated that almost $50 \%$ of patients treated with RC for clinical T1G3 UCB were upstaged to muscleinvasive disease (MIBC) with $33.4 \%$ having non-organconfined disease [2]. A reliable prediction of locally advanced stages of UCB may help improve risk stratification and thus optimize the selection of candidates for multimodal treatment. The quality of treatment may be increased by better patient counseling on neoadjuvant chemotherapy (NAC), intraoperative strategies, for example, extended lymphadenectomy, as well as nervesparing techniques and choice of urinary diversion.

Nomograms have been developed to predict locally advanced UCB or the likelihood of upstaging at the time of RC $[3,4]$. An external validation of 2 nomograms demonstrated that the ability to predict $\mathrm{pT} 3 / 4$ stages or lymph node metastasis is limited and not necessarily conferrable to other cohorts $[3,5]$.

In order to optimize the accuracy of existing prediction tools, a statistical adjustment for relevant preoperative parameters is important. Taking into account multiple clinical variables in the preoperative setting, we developed and validated a pre-cystectomy nomogram using preoperative variables in order to predict locally advanced UCB.

\section{Materials and Methods}

\section{Study Population}

This study was approved by an institutional review board with all participating sites providing the necessary data-sharing agreement within the 'PROspective MulticEnTer RadIcal Cystectomy Series 2011' (PROMETRICS 2011). A total of 18 European centers (15 German, 2 Austrian, and 1 Italian) prospectively collected data resulting in a database comprising 679 consecutive patients undergoing RC for muscle-invasive or high-risk bladder cancer between January 1, 2011 and December 31, 2011. A total of 342 patients (50.3\%) were excluded due to missing information on lymphovascular invasion $(\mathrm{LVI})(\mathrm{n}=177)$ and muscularis propria $(\mathrm{n}=119)$ at the time of last TUR-BT or evidence of distant metastases $(n=46)$. In total, 337 patients were eligible for the final analysis in the current investigation.

\section{Data Assessment}

Preoperative baseline patient characteristics were assessed and documented at admission for RC and included continuous variables such as age, gender and the number of TUR-BT. Categorical variables that were recorded at time of TUR-BT before RC were American Society of Anaesthesiologists Score (ASA, coded ASA1/2 vs. ASA3/4), tumor stage (coded $\geq \mathrm{cT} 3$ vs. cT2 vs. cTa, cTis, cT1), concomitant carcinoma in situ (CIS, coded presence vs. absence), tumor grading (coded G2/3 vs. G1), LVI (coded presence vs. absence) and tumor stage depending on the presence of muscularis propria in the specimen (coded $\geq \mathrm{cT} 2$ vs. $\mathrm{cTa}$, cTis, $\mathrm{cT} 1$ without muscularis propria and $\geq \mathrm{cT} 2$ vs. cTa, cTis, $\mathrm{cT} 1$ with presence of non-tumor-infiltrated muscularis propria). In addition, tumor stage (coded $\geq \mathrm{T} 3$ vs. $<\mathrm{T} 3$ ) and/or nodal stage (coded N+ vs. N-) at the computed tomography (CT), hydronephrosis (coded presence vs. absence) before RC and NAC (coded administered vs. not administered) were assessed as well. NAC was recorded only when patients received at least one complete cycle of chemotherapy. Histopathological stages were classified according to the 2009 TNM classification [6]. Histopathological evaluation was conducted by experienced uropathologists at each center according to standard protocols. Radiological evaluation in terms of clinical tumor and nodal stage was assessed by pre-RC imaging (CT) performed by experienced radiologists. The objective of our study was to evaluate the impact of clinicopathological features obtained from the last TUR-BT and preoperative staging imaging before RC on the prediction of a locally advanced tumor stage $\mathrm{pT} 3 / 4$ and/or $\mathrm{pN}+$.

\section{Statistical Analysis}

Medians and interquartile ranges (IQR) were generated for continuously coded variables; frequencies and proportions were generated for categorical variables. The Mann-Whitney and Chi-square test were used to assess differences in medians and proportions, respectively. Univariate and multivariate logistic regression models were calculated to evaluate the impact of age, gender, ASA-score, number of TUR-BTs before RC, tumor stage, CIS, tumor grading, LVI, tumor stage depending on the presence of muscularis propria in the specimen at the last TUR-BT before RC, tumor and nodal stage at CT, preoperative hydronephrosis and the administration of NAC on the prediction of a locally advanced tumor stage $\mathrm{pT} 3 / 4$ and/or $\mathrm{pN}+$ at RC. Backward elimination relied on Akaike's information criterion to identify the most informative predictors of a locally advanced tumor stage after RC [7]. Based on
58

Urol Int 2016;96:57-64

DOI: $10.1159 / 000433606$
Martini et al. 
the logistic regression coefficients, a nomogram to individually predict the risk of $\mathrm{pT} 3 / 4$ and/or $\mathrm{pN}+$ tumor stage was developed. A calibration plot graphically explored the correlation between model predicted and observed regarding $\mathrm{pT} 3 / 4$ and/or $\mathrm{pN}+$ at RC. The internal validity of the models was evaluated by bootstrapping. In 1,000 bootstrap samples, the coefficients of the final regression model were estimated and tested in the original sample. The difference between the coefficients in the original sample and bootstrap samples as reflected by the slope index is the measure for the amount of 'optimism'. Normally, slope values are located between 0 and 1. A slope value of 1 means no optimism. PA of each model was quantified using the area under the receiver operating characteristics curve [8].

The decision curve analysis (DCA) was carried out to evaluate the clinical value of the prediction of $\mathrm{pT} 3 / 4$ and/or $\mathrm{pN}+$ of our newly developed model vs. none, all and clinical tumor stage $\geq 2$ at the last TUR-BT before RC $[9,10]$. Analyses were conducted using the R statistical package (v.2.12.2) and the Statistical Package for Social Science 20.0 (SPSS Inc., Chicago, Ill., USA). All tests were two-sided with the statistical significance level set at $\mathrm{p} \leq 0.05$.

\section{Results}

\section{Descriptive Characteristics}

A total of $50.4 \%(n=170)$ displayed a locally advanced tumor stage $\mathrm{pT} 3 / 4$ and/or $\mathrm{pN}+$ at RC. The distribution of tumor stages $\mathrm{pT} 3 / 4, \mathrm{pN}+$ and $\mathrm{pT} 3 / 4$ and/or $\mathrm{pN}+$ at $\mathrm{RC}$ was $44.2,27.6$ and $50.4 \%$, respectively. Table 1 gives a detailed illustration of the descriptive characteristics. The number of TUR-BTs before RC $(\mathrm{p}=0.032)$, higher clinical tumor stage $(\mathrm{p}<0.001)$, presence of concomitant CIS $(p=0.037)$, presence of LVI $(p=0.011)$, higher clinical tumor stage in dependence of the muscularis propria $(\mathrm{p}<$ $0.001)$, tumor stage $<\mathrm{T} 3$, nodal stage $\mathrm{N}-$ at $\mathrm{CT}(\mathrm{p}<0.001)$ and hydronephrosis before RC ( $<<0.001)$ were significantly associated with a locally advanced tumor stage pT3/4 and/or pN+, respectively (table 1 ).

\section{Prediction of $p \mathrm{~T} 3 / 4$ and/or $p N+$}

Clinical tumor stage $\geq \mathrm{cT} 3$ vs. cTa, cTis, cT1 (odds ratio (OR) 4.342; $\mathrm{p}<0.001$ ) and clinical tumor stage $\mathrm{cT} 2$ vs. cTa, cTis, cT1 (OR 3.889; $\mathrm{p}=0.030$ ), concomitant CIS (OR 0.564; $\mathrm{p}=0.031)$, LVI (OR 2.224; $\mathrm{p}=0.010)$, clinical tumor stage in dependence of muscularis propria $\geq \mathrm{cT} 2$ vs. cTa, cTis, cT1 with presence of tumor-free muscularis propria (OR 3.292; p < 0.001), hydronephrosis (OR 2.644; $\mathrm{p}<0.001$ ), tumor stage $\geq \mathrm{T} 3$ and/or $\mathrm{N}+$ at CT (OR 5.053; $\mathrm{p}<0.001$ ), respectively, were significantly associated with $\mathrm{pT} 3 / 4$ and/or $\mathrm{pN}+$ at $\mathrm{RC}$ in univariate logistic regression analysis (table $2 \mathrm{a}$ ).

In multivariate logistic regression analysis addressing the prediction of $\mathrm{pT} 3 / 4$ and/or $\mathrm{pN}+$, age (OR 0.980; $\mathrm{p}<$
0.001 ), clinical tumor stage $\geq \mathrm{cT} 3$ vs. cTa, cTis, $\mathrm{cT} 1$ (OR 3.367; $\mathrm{p}<0.001)$, clinical tumor stage $\mathrm{cT} 2$ vs. cTa, cTis, cT1 (OR 3.476; $\mathrm{p}=0.058$ ), hydronephrosis (OR 1.844; $\mathrm{p}=$ 0.043 ), and tumor stage $\geq \mathrm{T} 3$ and/or $\mathrm{N}+$ at $\mathrm{CT}$ (OR 4.378; $\mathrm{p}<0.001)$, respectively, were the final variables of the model calculated in backward elimination (table 2b). The slopes of this model after 1,000 bootstrap samples within the internal validation were between 0.76 and 0.89 . The inherent nomogram of our newly developed model can be seen in figure la showing a predictive accuracy (PA) of $77.5 \%$ in our study population.

In addition, the DCA showed that the application of our nomogram predicting $\mathrm{pT} 3 / 4$ and/or $\mathrm{pN}+$ at $\mathrm{RC}$ was associated with a higher net benefit over all thresholds compared to a clinical tumor stage $\geq \mathrm{cT} 2$ (fig. 1b).

Compared to a reduced model (cT-stage of TUR-BT and radiological assessment), our nomogram always shows a net benefit above the $42 \%$ threshold (fig. 1c).

\section{Discussion}

Locally advanced UCB (stage pT3/4 and/or pN+) is associated with reduced long-term survival following $\mathrm{RC}[1,11]$. Staging before RC is often inaccurate and the discrepancy between staging based on TUR-BT and final tumor stage of the cystectomy specimen represents a significant problem $[2,12-14]$. Among potential reasons for this phenomenon are varying quality of TUR-BT, low sensitivity of preoperative staging and increasing time intervals between TUR-BT and RC $[1,3]$. An exact staging and prediction of advanced UCB is an essential requirement for adequate clinical decision making. We developed a pre-cystectomy nomogram including age, clinical tumor stage $\geq c \mathrm{~T} 3$, presence of hydronephrosis before $\mathrm{RC}$ and tumor stage $\geq \mathrm{T} 3$ or $\mathrm{N}+$ at CT imaging in order to predict $\mathrm{pT} 3 / 4$ and/or $\mathrm{pN}+$ at $\mathrm{RC}$. The PA of our nomogram was $77.5 \%$ and showed a net benefit by DCA.

A pre-cystectomy nomogram for the prediction of advanced UCB stage has previously been developed by Karakiewicz et al. [3]. Multivariate models for the prediction of tumor stages $\mathrm{pT} 3 / 4$ and $\mathrm{pN}+$ showed an accuracy of 75.7 and $63.1 \%$, respectively. The nomograms were more accurate than the tumor stage at TUR-BT alone [3]. May et al. [5] externally validated both nomograms implemented by Karakiewicz based on data of 2,477 patients of a German cohort treated by RC. They found a relatively low PA of 67.5 and $54.5 \%$ for the prediction of tumor stage $\mathrm{pT} 3 / 4$ and $\mathrm{pN}+$, respectively [5]. The predic- 
Table 1. Descriptive characteristics

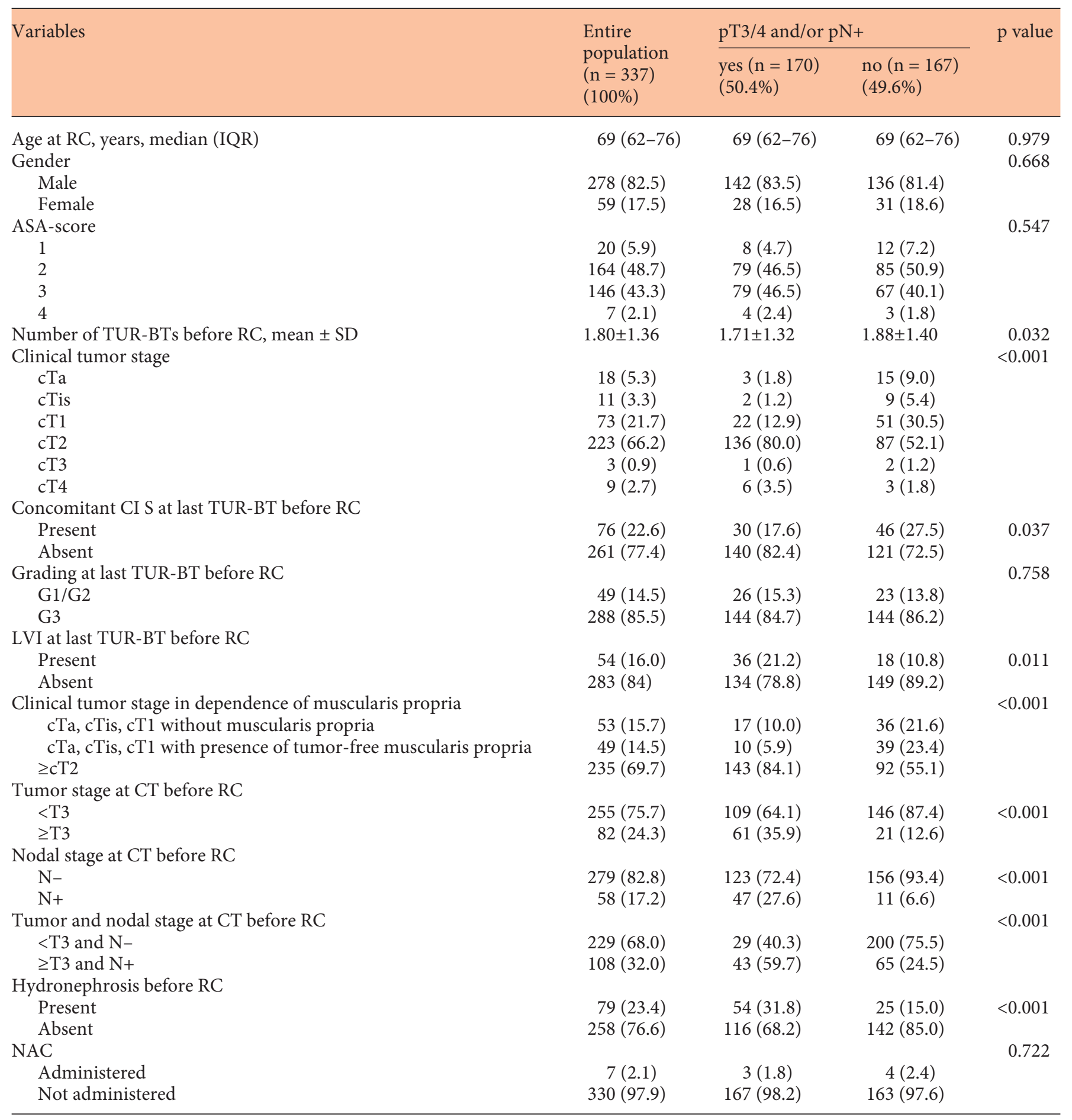

Figures in parentheses are percentages.

$\mathrm{SD}=$ Standard deviation; $\mathrm{c}=$ clinical tumor stage in TUR-BT specimen . 
Table 2. Prediction of $\mathrm{pT} 3 / 4$ and/or $\mathrm{pN}+$ at $\mathrm{RC}$

a Univariate logistic regression model addressing prediction of $\mathrm{pT} 3 / 4$ and/or $\mathrm{pN}+$ at $\mathrm{RC}$

\begin{tabular}{|c|c|c|c|c|}
\hline \multirow[t]{3}{*}{ Variables } & \multicolumn{4}{|c|}{ Prediction of $\mathrm{pT} 3 / 4$ and/or $\mathrm{pN}+$ at $\mathrm{RC}$} \\
\hline & \multirow[t]{2}{*}{ OR } & \multicolumn{2}{|c|}{ 95\% confidence interval } & \multirow[t]{2}{*}{$\mathrm{p}$ value } \\
\hline & & lower & upper & \\
\hline Age at RC (cont.) & 1.002 & 0.981 & 1.024 & 0.846 \\
\hline Female gender (ref.: male) & 0.865 & 0.493 & 1.518 & 0.614 \\
\hline Number of TUR-BTs before RC (cont.) & 0.911 & 0.776 & 1.071 & 0.258 \\
\hline \multicolumn{5}{|l|}{ Clinical tumor stage } \\
\hline$\geq \mathrm{cT} 3$ vs. cTa, cTis, cT1 & 4.342 & 2.593 & 7.272 & $<0.001$ \\
\hline$\geq \mathrm{cT} 2$ vs. cTa, cTis, cT1 & 3.889 & 1.138 & 13.292 & 0.030 \\
\hline Tumor grading G2/G3 at last TUR-BT before RC (ref.: G1) & 0.885 & 0.482 & 1.623 & 0.692 \\
\hline Presence of concomitant CIS at last TUR-BT before RC (ref.: absence) & 0.564 & 0.335 & 0.948 & 0.031 \\
\hline Presence of LVI at last TUR-BT before RC (ref.: absence) & 2.224 & 1.206 & 4.101 & 0.010 \\
\hline \multicolumn{5}{|l|}{ Clinical tumor stage in dependence of muscularis propria } \\
\hline$\geq \mathrm{cT} 2$ vs. cTa, cTis, cT1 without muscularis propria & 0.543 & 0.220 & 1.339 & 0.185 \\
\hline$\geq \mathrm{cT} 2$ vs. cTa, cTis, cT1 with presence of tumor-free muscularis propria & 3.292 & 1.747 & 6.202 & $<0.001$ \\
\hline Presence of hydronephrosis before RC (ref.: absence) & 2.644 & 1.550 & 4.509 & $<0.001$ \\
\hline ASA-score $3 / 4$ at RC (ref.: ASA-score $1 / 2$ ) & 1.322 & 0.860 & 2.032 & 0.203 \\
\hline No administration of NAC (ref.: administration) & 0.732 & 0.161 & 3.322 & 0.686 \\
\hline Tumor stage $\geq \mathrm{T} 3$ and/or $\mathrm{N}+$ at CT before $\mathrm{RC}$ (ref.: $<\mathrm{T} 3$ and $\mathrm{pN}-$ ) & 5.053 & 3.019 & 8.460 & $<0.001$ \\
\hline
\end{tabular}

b Final step of the backward eliminated multivariate regression model addressing the prediction of $\mathrm{pT} 3 / 4$ and/or $\mathrm{pN}+$ at $\mathrm{RC}$

\begin{tabular}{|c|c|c|c|c|}
\hline \multirow[t]{2}{*}{ Variables } & \multicolumn{4}{|c|}{ Prediction of tumor stage $\mathrm{pT} 3 / 4$ and/or nodal stage $\mathrm{pN}+$ at $\mathrm{RC}$} \\
\hline & OR & \multicolumn{2}{|c|}{$95 \%$ confidence interval } & $\mathrm{p}$ value \\
\hline Age at RC (cont.) & 0.980 & 0.973 & 0.987 & $<0.001$ \\
\hline \multicolumn{5}{|l|}{ Clinical tumor stage } \\
\hline Presence of hydronephrosis at RC (ref.: absence) & 1.844 & 1.019 & 3.336 & 0.043 \\
\hline Tumor stage $\geq \mathrm{T} 3$ and/or $\mathrm{N}+$ at $\mathrm{CT}$ before $\mathrm{RC}$ (ref.: $<\mathrm{T} 3$ and $\mathrm{N}-$ ) & 4.378 & 2.533 & 7.566 & $<0.001$ \\
\hline
\end{tabular}

tive ability of both nomograms presented by Karakiewicz was not conferrable to patients of the German cohort because the number of locally advanced UCB was underestimated [5]. The authors stated that the development of new models to predict advanced UCB with a higher PA is needed.

We considered additional clinical parameters for the generation of our model: LVI at last TUR-BT before RC, clinical tumor stage according to muscularis propria ( $\geq \mathrm{cT} 2$ vs. cTa, cTis, cT1 without muscularis propria; $\geq$ cT2 vs. cTa, cTis, cT1 with presence of non-tumor-infiltrated muscularis propria), tumor and nodal stage at CT imaging ( $\geq \mathrm{T} 3$ vs. $\leq \mathrm{T} 3$ or $\mathrm{N}+$ vs. $\mathrm{N}-$ ) and the presence of hydronephrosis before RC. The PA was increased by integrating these factors, which are part of routine diagnostic algorithms. It has been shown that the presence of LVI in TUR-BT specimens was significantly associated with $\mathrm{pT} 3 / 4$ and/or $\mathrm{pN}+$ only in univariate analysis $(\mathrm{p}=$ 0.010 ). Green et al. [4] demonstrated that the presence of LVI in the TUR-BT specimen is associated with the presence of $\mathrm{pN}+$ stage independently.

Although the presence of LVI in TUR-BT was not an independent predictor in our final model, it may add relevant information for the prediction of advanced tumor stages. Patients with cT2-tumor stage without LVI had a $57.3 \%$ probability of $\mathrm{pT} 3 / 4$ and/or $\mathrm{pN}+$ in the final pathological evaluation versus $75.6 \%$ in patients with cT2 and detected LVI $(\mathrm{p}=0.027)$. 


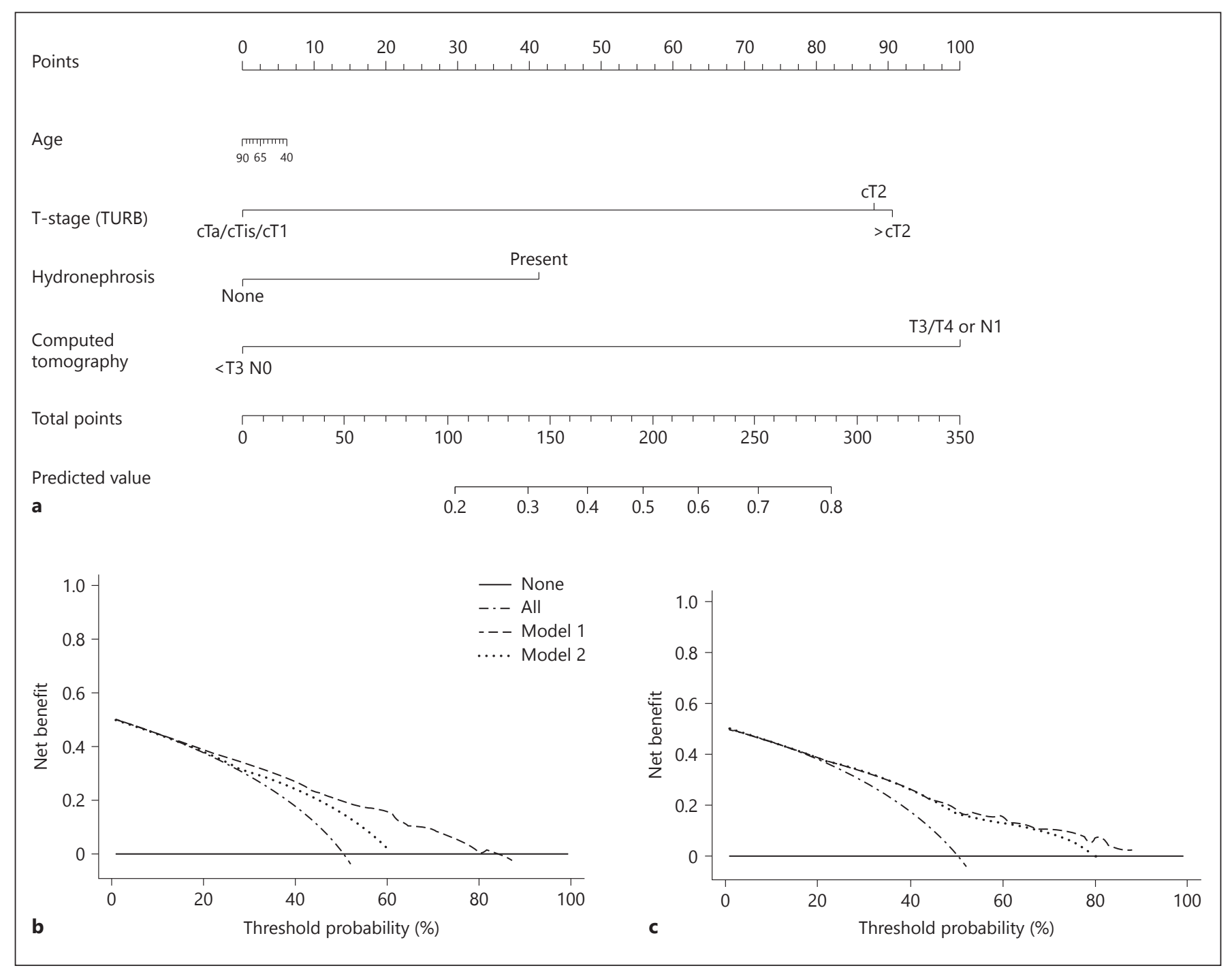

Fig. 1. a Nomogram for the prediction of $\mathrm{pT} 3 / 4$ and/or $\mathrm{pN}+$. To obtain the nomogram-predicted probability of $\mathrm{pT} 3 / 4$ and/or $\mathrm{pN}+$ at RC, locate the patient values on each axis. Draw a vertical line to the 'points'-axis to determine how many points are attributed for each variable value. Add the points of all variables. Locate the sum on the 'total points' line to assess the individual probability of the respective stages at RC. $\mathbf{b}$ DCA showing the net benefit associated with the use of the models for prediction of $\mathrm{pT} 3 / 4$ and/or $\mathrm{pN}+$ at
RC. Model 1 (dashed line) refers to our newly developed nomogram. Model 2 (dotted line) refers to the prediction of $\mathrm{pT} 3 / 4$ and or $\mathrm{pN}+$ according to the variable $\geq \mathrm{cT} 2$. $\mathrm{c}$ DCA showing the net benefit associated with the use of the models for prediction of pT3/4 and/or pN+ at RC. Model 1 (dashed line) refers to our newly developed nomogram. Model 2 (dotted line) refers to the prediction of $\mathrm{pT} 3 / 4$ and or $\mathrm{pN}+$ according to the reduced model (cTstage of TUR-BT and radiological assessment at CT).
The quality of TUR-BT and related clinical tumor stage plays an important role for the prediction of definite tumor stage. For an improved accuracy of the clinical tumor stage in TUR-BT specimens, we included the presence of a tumor-free muscularis propria in TUR-BT specimens. We discovered that the factor $\geq \mathrm{cT} 2$ vs. cTa, cTis, cT1 with the presence of tumor-free muscularis propria was significantly associated with $\mathrm{pT} 3 / 4$ and/or
$\mathrm{pN}+$ only in univariate analysis $(\mathrm{p}<0.001)$. In our multivariate model, lower patient age was an independent predictor for advanced tumor stage (OR 0.980; $\mathrm{p}<0.001$ ). This fact is contrary to the results of Karakiewicz et al. [3]. One might conclude that younger patients with MIBC in particular may benefit from an early RC because of their higher probability of having advanced tumor stage. 
Considering the important role of modern imaging methods for clinical staging prior to $\mathrm{RC}$, the integration of $\mathrm{cT}$ - and $\mathrm{cN}$-stage by preoperative imaging appeared essential when generating our nomogram. In our cohort, an advanced tumor stage on preoperative CT imaging $\geq \mathrm{T} 3$ and/or $\mathrm{N}+$ was an independent predictor for tumor stage $\mathrm{pT} 3 / 4$ and/or $\mathrm{pN}+(\mathrm{OR} 4.378 ; \mathrm{p}<0.001)$ at RC. Stimson et al. [15] previously described the association of preoperative hydronephrosis with the presence of nonorgan-confined UCB with lymph node metastases at the time of RC. In our cohort, the presence of hydronephrosis was identified as an independent predictor for advanced tumor stage $\mathrm{pT} 3 / 4$ and/or $\mathrm{pN}+(\mathrm{OR} 1.844 ; \mathrm{p}=$ $0.043)$.

The use of a pre-cystectomy nomogram with a high PA regarding the presence of advanced tumor stages may help the clinician to decide whether or not to apply NAC. NAC may have a beneficial effect by downstaging and reducing the probability of a positive surgical resection margin as well as in an early treatment of potential micrometastases [16, 17]. Grossman et al. [18] demonstrated that patients with locally advanced UCB benefitted from NAC when compared to RC alone in the SWOG S8710 study. Using low risk and high risk features, Culp et al. [19] also identified patients with a poor prognosis who are most likely to benefit from NAC. However, NAC is rarely practiced. Possible reasons for the underutilization of NAC remain still unclear but could be explained by concerns regarding efficacy and potential delay of RC. In a recent study only $12 \%$ of the patients with clinical tumor stages pT2-T4aN0M0 received NAC whereas $22 \%$ received adjuvant chemotherapy [20]. Similarly, only a small proportion of patients received NAC in the present study: altogether, 7 patients $(2.1 \%)$ with NAC were included in the study population. A sensitivity analysis of the 330 patients without NAC (data not shown) showed the same results as mentioned above.

This study is limited by the heterogeneous cohort composed by patients treated at different centers in Germany, Austria and Italy with different surgical practices such as extent of lymphadenectomy, histopathological assessment or quality of TUR-BT. Another limitation displays the lack of a standard template of lymph node dissection. However, pelvic lymph node dissection was performed routinely and the extension of the dissection was based on preoperative CT scan and suspicious intraoperative findings. Other important limitations were the lack of a central pathology and radiology review as well as the differences in clinical pathways, postoperative monitoring and follow-up.

\section{Conclusion}

We developed a new nomogram for the prediction of locally advanced tumor stage pT3/4 and/or pN+ before RC using established clinicopathological parameters. The high PA and easy application may allow the use of our nomogram in daily clinical practice. An external validation of our model is required.

\section{Acknowledgments}

We would like to thank the members of the PROMETRICS 2011 research group for their valuable effort: Christian Gilfrich, Hans-Martin Fritsche, Alexander Buchner, Jörg Ellinger, Isabella Syring, Wolfgang Weidner, Melanie Durschnabel, Günter Janetschek, Christoph Wiesner, Georg Bartsch, Gördük, Murat, Chris Protzel, Rudolf Moritz, Joachim Noldus, Rein-Jüri Palisaar, Vladimir Novotny, Sascha Pahernik, Boris Hadaschik, Roman Mayr, Florian Hartmann, Paul Schramek.

\section{References}

1 Jacobs BL, Lee CT, Montie JE: Bladder cancer in 2010: how far have we come? CA Cancer J Clin 2010;60:244-272.

- 2 Fritsche HM, Burger M, Svatek RS, Jeldres C, Karakiewicz PI, Novara G, Skinner E, Denzinger S, Fradet Y, Isbarn H, Bastian PJ, Volkmer BG, Montorsi F, Kassouf W, Tilki D, Otto W, Capitanio U, Izawa JI, Ficarra V, Lerner S, Sagalowsky AI, Schoenberg M, Kamat A, Dinney CP, Lotan Y, Shariat SF: Characteristics and outcomes of patients with clinical T1 grade 3 urothelial carcinoma treated with radical cystectomy: results from an international cohort. Eur Urol 2010;57:300309.

Prediction of Locally Advanced Tumor Stage
3 Karakiewicz PI, Shariat SF, Palapattu GS, Perrotte P, Lotan Y, Rogers CG, Amiel GE, Vazina A, Gupta A, Bastian PJ, Sagalowsky AI, Schoenberg M, Lerner SP: Precystectomy nomogram for prediction of advanced bladder cancer stage. Eur Urol 2006;50:1254-1260; discussion 1261-1262.

4 Green DA, Rink M, Hansen J, Cha EK, Robinson B, Tian Z, Chun FK, Tagawa S, Karakiewicz PI, Fisch M, Scherr DS, Shariat SF: Accurate preoperative prediction of non-organconfined bladder urothelial carcinoma at cystectomy. BJU Int 2013;111:404-411.

-5 May M, Burger M, Brookman-May S, Otto W, Peter J, Rud O, Fritsche HM, Bolenz C, Trojan
L, Herrmann E, Michel MS, Wülfing C, Moritz R, Tiemann A, Müller SC, Ellinger J, Buchner A, Stief CG, Tilki D, Wieland WF, Gilfrich C, Höfner T, Hohenfellner M, Haferkamp A, Roigas J, Bretschneider-Ehrenberg P, Müller O, Zacharias M, Gunia S, Bastian PJ: [Validation of pre-cystectomy nomograms for the prediction of locally advanced urothelial bladder cancer in a multicentre study: are we able to adequately predict locally advanced tumour stages before surgery?]. Urologe A 2011;50:706-713.

6 Greene FL, Wittekend C, et al: American Joint Committee on Cancer (AJCC) Staging Manual, ed 7. Philadelphia, Springer, 2009. 
7 Hens N, Aerts M, Molenberghs G: Model selection for incomplete and design-based samples. Stat Med 2006;25:2502-2520.

8 Harrell FE Jr, Lee KL, Mark DB: Multivariable prognostic models: issues in developing models, evaluating assumptions and adequacy, and measuring and reducing errors. Stat Med 1996; 15:361-387.

-9 Vickers AJ, Elkin EB: Decision curve analysis: a novel method for evaluating prediction models. Med Decis Making 2006;26:565-574.

10 Zaak D, Burger M, Otto W, Bastian PJ, Denzinger S, Stief CG, Buchner H, Hartmann A, Wieland WF, Shariat SF, Fritsche HM: Predicting individual outcomes after radical cystectomy: an external validation of current nomograms. BJU Int 2010;106:342-348.

11 Witjes JA, Compérat E, Cowan NC, De Santis M, Gakis G, Lebret T, Ribal MJ, Van der Heijden AG, Sherif A: EAU guidelines on muscleinvasive and metastatic bladder cancer: summary of the 2013 guidelines. Eur Urol 2014; 65:778-792.

12 Svatek RS, Shariat SF, Novara G, Skinner EC, Fradet Y, Bastian PJ, Kamat AM, Kassouf W, Karakiewicz PI, Fritsche HM, Izawa JI, Tilki
D, Ficarra V, Volkmer BG, Isbarn H, Dinney CP: Discrepancy between clinical and pathological stage: external validation of the impact on prognosis in an international radical cystectomy cohort. BJU Int 2011;107:898-904.

13 Shariat SF, Palapattu GS, Karakiewicz PI, Rogers CG, Vazina A, Bastian PJ, Schoenberg MP, Lerner SP, Sagalowsky AI, Lotan Y: Discrepancy between clinical and pathologic stage: impact on prognosis after radical cystectomy. Eur Urol 2007;51:137-149; discussion 149-151.

-14 Bianco FJ Jr, Justa D, Grignon DJ, Sakr WA, Pontes JE, Wood DP Jr: Management of clinical T1 bladder transitional cell carcinoma by radical cystectomy. Urol Oncol 2004;22:290294.

15 Stimson CJ, Cookson MS, Barocas DA, Clark PE, Humphrey JE, Patel SG, Smith JA Jr, Chang SS: Preoperative hydronephrosis predicts extravesical and node positive disease in patients undergoing cystectomy for bladder cancer. J Urol 2010;183:1732-1737.

16 Sonpavde G, Sternberg CN: Neoadjuvant systemic therapy for urological malignancies. BJU Int 2010;106:6-22.
17 Clark PE: Neoadjuvant versus adjuvant chemotherapy for muscle-invasive bladder cancer. Expert Rev Anticancer Ther 2009;9:821830 .

-18 Grossman HB, Natale RB, Tangen CM, Speights VO, Vogelzang NJ, Trump DL, deVere White RW, Sarosdy MF, Wood DP Jr, Raghavan D, Crawford ED: Neoadjuvant chemotherapy plus cystectomy compared with cystectomy alone for locally advanced bladder cancer. N Engl J Med 2003;349:859866.

19 Culp SH, Dickstein RJ, Grossman HB, Pretzsch SM, Porten S, Daneshmand S, Cai J, Groshen S, Siefker-Radtke A, Millikan RE, Czerniak B, Navai N, Wszolek MF, Kamat AM, Dinney CP: Refining patient selection for neoadjuvant chemotherapy before radical cystectomy. J Urol 2014;191:40-47.

20 Feifer A, Taylor J, Shouery M, et al; B.C.A.N. Muscle-Invasive Bladder Cancer Quality of Care Consortium: Multi-institutional quality-of-care initiative for non-metastatic, muscle-invasive, transitional cell carcinoma of the bladder. J Clin Oncol 2011;29(suppl 7):abstr 240 . 